\title{
Transmission potential of the entomopathogenic fungi Isaria fumosorosea and Beauveria bassiana from sporulated cadavers of Diaphorina citri and Toxoptera citricida to uninfected $D$. citri adults
}

\author{
Marcos Roberto Conceschi • Celeste Paola D'Alessandro (iD) \\ Rafael de Andrade Moral - Clarice Garcia Borges Demétrio • \\ Italo Delalibera Júnior
}

Received: 22 May 2015/ Accepted: 17 March 2016/Published online: 24 March 2016

(C) International Organization for Biological Control (IOBC) 2016

\begin{abstract}
Diaphorina citri Kuwayama (Hemiptera: Liviidae) is the vector of the causal agent of Huanglongbing disease, and Toxoptera citricida Kirkaldy (Hemiptera: Aphididae) is the vector of the citrus tristeza virus. D. citri and T. citricida share the same habitat and both are susceptible to Beauveria bassiana and Isaria fumosorosea. Therefore, the aim of this study was to evaluate the horizontal transmission of $B$. bassiana ESALQ-PL63 and I. fumosorosea ESALQ1296 between $D$. citri cadavers and uninfected $D$. citri
\end{abstract}

Handling Editor: Nicolai Meyling.

M. R. Conceschi · C. P. D’Alessandro $(\varangle)$ · I. D. Júnior Department of Entomology and Acarology, "Luiz de Queiroz" College of Agriculture (ESALQ), University of São Paulo (USP), Av. Padua Dias, 11,

P.O. Box 9, Piracicaba, São Paulo CEP 13418-900, Brazil e-mail: celed1881@gmail.com;

celeste.dalessandro@usp.br

M. R. Conceschi

e-mail: marcosrconceschi@yahoo.com.br

I. D. Júnior

e-mail: delalibera@usp.br

Rafael de AndradeMoral · C. G. B. Demétrio

Department of Exact Sciences, "Luiz de Queiroz"

College of Agriculture (ESALQ), University of São Paulo

(USP), Av. Padua Dias, 11, P.O. Box 9, Piracicaba,

São Paulo CEP 13418-900, Brazil

e-mail: rafael_moral@yahoo.com.br

C. G. B. Demétrio

e-mail: clarice.demetrio@usp.br adults, as well as between $T$. citricida cadavers and uninfected $D$. citri adults under laboratory and semifield conditions. In the laboratory, the presence of one to ten $D$. citri cadavers infected with $B$. bassiana and $I$. fumosorosea in citrus plants resulted in mortality rates of D. citri adults ranging from 51.2 to $81.9 \%$ and 36.2 to $68 \%$, respectively. When $T$. citricida cadavers were used, the mortality rates of uninfected $D$. citri adults ranged from 35.4 to $87.7 \%$ with $B$. bassiana and from 41.7 to $80.4 \%$ with I. fumosorosea. The horizontal transmission was also confirmed under semi-field conditions. The results indicate that the control of D. citri using I. fumosorosea and $B$. bassiana can be promoted through conidial cycling in $T$. citricida, by generating new infection cycles, which may contribute to the overall performance of microbial control in citrus.

Keywords Biological control - Citrus pests . Entomopathogen - Horizontal transmission ·

Diaphorina citri $\cdot$ Toxoptera citricida

\section{Introduction}

Direct and indirect damage caused by pests are important factors that result in citrus yield losses. Diaphorina citri Kuwayama (Hemiptera: Liviidae) and Toxoptera citricida Kirkaldy (Hemiptera: Aphididae) are vectors of two important diseases: citrus greening, or huanglongbing (HLB) disease, and citrus 
tristeza (CTV), respectively (Bové 2006; Michaud 1998). HLB is caused by the bacteria 'Candidatus Liberibacter spp.', which are transmitted by $D$. citri and affect citrus production in India, China, Indonesia, South Africa and Brazil (Kuchment 2013). These pests are usually controlled through intensive applications of agrochemicals, which may result in side effects such as target pest resurgence, secondary pest outbreaks and phytosanitary product resistance (Gravena 2005).

Entomopathogenic fungi are important natural enemies of pests because they infect a large number of arthropods, and under favorable conditions, they can initiate epizootics in the field (Alves 1998). The pathogenicity of certain fungal species to $D$. citri has been reported, such as Isaria fumosorosea, Beauveria bassiana, Hirsutella citriformis, Lecanicillium lecanii, L. muscarium, L. longisporum, Metarhizium anisopliae and M. brunneum (Ascomycota: Hypocreales) (Avery et al. 2009; Casique-Valdes et al. 2011; Gandarilla-Pacheco et al. 2013; Hall et al. 2012; Hoy et al. 2010; Hunter et al. 2011; Lezama-Gutiérrez et al. 2012; Meyer et al. 2007, 2008; Padulla and Alves 2009; Pinto et al. 2012; Stauderman et al. 2012; Subandiyah et al. 2000; Yang et al. 2006). The entomopathogenic fungi I. fumosorosea, B. bassiana, L. lecanii and M. anisopliae have been reported as pathogens of T. citricida (Balfour and Khan 2012; Hernández-Torres et al. 2006; Pick et al. 2012; Poprawski et al. 1999).

The dissemination and transmission of entomopathogenic fungi are important factors for determining their potential as microbial control agents of pests in agroecosystems. An important characteristic of entomopathogenic fungi is the dissemination of conidia in the environment due to both abiotic (wind, rain or dew) and biotic (primary or secondary host, parasites, predators, birds and mammals) factors (Hesketh et al. 2010). The conidia present on an insect can be transferred to the same or different species of insects by horizontal transmission (Harper 1987), and they can develop new infection cycles and natural epizootics in the field (Hajek and St. Leger 1994).

Several studies have confirmed the horizontal transmission of the entomopathogenic fungi $B$. bassiana, M. anisopliae and I. fumosorosea in agricultural pests through the transmission of conidia between sporulating and uninfected individuals
(Avery et al. 2010; Long et al. 2000; Lopes et al. 2011; Sanjaya et al. 2013; Svedese et al. 2013) as well as between females and males of the same species during copulation (García-Munguía et al. 2011; Quesada-Moraga et al. 2008; Toledo et al. 2007). Avery et al. (2009) demonstrated in laboratory tests that $83 \%$ of $D$. citri adults exposed to yellow cards sprayed with I. fumosorosea blastopores became infected and cadavers developed conidia externally. Furthermore, Moran et al. (2011) showed that inoculation of $I$. fumosorosea blastopores on yellow cards resulted in less than $40 \%$ of $D$. citri infected after three weeks of confinement in plastic boxes under semi-field conditions. However, the transmission and dissemination potential of entomopathogenic fungi from sporulating cadavers without introduction of artificial inoculation devices have not been reported in citrus pests.

The aphid T. citricida shares the same habitat of young leaves and citrus shoots with $D$. citri (Gravena 2005). Because of its larger size and generally large population densities relative to $D$. citri, the host $T$. citricida may serve as an important source of inoculum in the transmission of $B$. bassiana and $I$. fumosorosea to D. citri. Therefore, the objective of the present study was to estimate the horizontal transmission of I. fumosorosea (ESALQ-1296) and B. bassiana (ESALQ-PL63) between sporulating cadavers and uninfected adult $D$. citri (intraspecific transmission) as well as between sporulating $T$. citricida cadavers and uninfected adult D. citri (interspecific transmission) under laboratory and semi-field conditions. I. fumosorosea ESALQ-1296 and $B$. bassiana ESALQ-PL63 were selected since they were shown to cause high levels of mortality and sporulation in D. citri and T. citricida (unpublished data). Also, B. bassiana ESALQ-PL63 is registered under the trade name Boveril ${ }^{\circledR}$ (Koppert Brazil), and $I$. fumosorosea ESALQ-1296 is under registration in Brazil.

\section{Materials and methods}

Diaphorina citri and Toxoptera citricida rearing

Diaphorina citri was reared on Murraya paniculata (Rutaceae) seedlings inside cages of $60 \times 60 \times$ $50 \mathrm{~cm}$ (height, width and depth) with a steel framework and walls covered with voile fabric. $T$. citricida 
was reared on Citrus sinensis (Rutaceae) plants, and the insects were confined in bags made of voile fabric. Both insects were maintained in a climate-contro lled room at $25 \pm 2{ }^{\circ} \mathrm{C}, 70-80 \% \mathrm{RH}$ and $14 \mathrm{~h}$ photophase.

\section{Fungal cultivation}

The entomopathogenic fungi I. fumosorosea ESALQ1296 and B. bassiana ESALQ-PL63 were obtained from the collection of entomopathogens of the Laboratory of Pathology and Microbial Control of Insects of the "Luiz de Queiroz" College of Agriculture (ESALQ), University of São Paulo (USP), which is located in Piracicaba, São Paulo State, Brazil. The ESALQ-1296 strain was obtained from adults of the whitefly Bemisia tabaci biotype B (Hemiptera: Aleyrodidae) collected in Jaboticabal, São Paulo, in 2001. The ESALQ-PL63 strain was isolated from Atta sp. (Hymenoptera: Formicidae) collected in Piracicaba, São Paulo, in 1992. The fungi were cultivated in $9 \mathrm{~cm}$ diameter Petri dishes containing Sabouraud dextrose agar medium supplemented with yeast extract (SDYA: $2.5 \mathrm{~g} \mathrm{l}^{-1}$ bacteriological peptone, $10 \mathrm{~g} \mathrm{l}^{-1}$ dextrose, $2.5 \mathrm{~g} \mathrm{l}^{-1}$ yeast extract and $20 \mathrm{~g} \mathrm{l}^{-1}$ bacteriological agar) and maintained in an incubator at $26 \pm 1{ }^{\circ} \mathrm{C}$ with a $12 \mathrm{~h}$ photophase for ten days.

\section{Obtaining sporulated cadavers}

Inocula of $B$. bassiana (ESALQ-PL63) and $I$. fumosorosea (ESALQ-1296) were produced on Petri dishes containing SDYA and conidia were harvested from the surface by scraping with a metallic spatula. Fungal suspensions at a concentration of $5 \times 10^{8}$ conidia $\mathrm{ml}^{-1}$ were prepared with Tween $80(0.01 \%)$ and homogenized with a Vortex ${ }^{\circledR}$ apparatus. Two hundred adults of $D$. citri or $T$. citricida were placed on young shoots of orange plants $(1 \mathrm{~m}$ height $)$ of the variety "Pera" (20 adults per plant). The plants were sprayed with $400 \mu \mathrm{l}$ of the conidial suspension of each fungus (five plants per fungus). Spraying was performed with an airbrush-type hand sprayer $\left(\right.$ SAGYMA $^{\circledR}$, model SW-168) at 10 PSI pressure. The sprayed plants were maintained in a climatecontrolled room at $25 \pm 2{ }^{\circ} \mathrm{C}, 70-80 \% \mathrm{RH}$ and $12 \mathrm{~h}$ photophase. At five days post-application, the dead insects were transferred to 24-well cell culture plates containing cotton moistened with sterile distilled water (humid chamber) and maintained for three days in an incubator at $26 \pm 1{ }^{\circ} \mathrm{C}$ with a $12 \mathrm{~h}$ photophase to promote sporulation.

\section{Quantification of sporulation}

All of the cadavers of D. citri or T. citricida showed abundant sporulation after pulverization of I. fumosorosea ESALQ-1296 and B. bassiana ESALQ-PL63. These adults were used to quantify the number of conidia per insect. Five sporulated cadavers of each insect species were chosen at random and placed together in Eppendorf tubes. Then, $1 \mathrm{ml}$ of $0.005 \%$ Tween 80 was added to the tubes, and the material was homogenized with a Vortex ${ }^{\circledR}$ apparatus to facilitate the removal of conidia from the surface of the insects. The total number of conidia was quantified in a Neubauer chamber, and the concentration of conidia per individual was estimated. For each insect species and fungus, four replicates were performed, and each replicate included five sporulated adults $(n=20)$.

Horizontal transmission test under laboratory conditions

The experimental unit consisted of a seedling of Citrus limonia measuring $15 \mathrm{~cm}$ in height, grown in a pot. The shoot was confined in a $500 \mathrm{ml}$ plastic cup with two openings $\left(45-50 \mathrm{~cm}^{2}\right)$ covered with voile fabric to allow aeration. The cups were maintained in plastic trays to facilitate irrigation. The sporulated $D$. citri or T. citricida cadavers were transferred to the plants with the aid of a fine insulin syringe needle, and uninfected adults were transferred with the aid of an aspirator. One, three, five or ten sporulated D. citri or $T$. citricida cadavers and 20 uninfected adult $D$. citri were introduced per plant. In the control group, 20 uninfected adult $D$. citri were transferred to the plants without adding any cadavers. All of the treatments were maintained in a climate-controlled room at $25 \pm 2{ }^{\circ} \mathrm{C}, 80 \pm 10 \% \mathrm{RH}$ and $12 \mathrm{~h}$ photophase for ten days. The dead insects were removed daily from the plastic cups to avoid the development of new cycles of infection or sporulation of new cadavers, which would increase the dose of conidia per plant. Two parameters were estimated on the 10th day based on the number of live and dead insects (mortality) and the number of insects that died during the study and sporulated (sporulation). Mortality was measured to 
estimate the efficacy of horizontal transmission from sporulated cadavers to uninfected insects, and sporulation was used to confirm that the mortality was caused by the fungal infection and to estimate the potential for new cycles of disease. The experimental design for $D$. citri and $T$. citricida was completely randomized, with at least three replicates per treatment, and all combinations (regarding fungus and cadaver numbers) were run at the same time. The experiment was performed separately for each insect pest and was carried out one time for T. citricida and three times on different dates for $D$. citri.

Horizontal transmission test under semi-field conditions

The semi-field assays were performed from March 2013 to April 2013 (D. citri $\rightarrow$ D. citri) and April 2013 to March 2014 (T. citricida $\rightarrow D$. citri) (Table 1) at the ESALQ-USP Campus, Piracicaba, São Paulo, Brazil. Orange plants (Citrus sinensis) of the variety 'Natal' measuring approximately $55 \mathrm{~cm}$ in height were placed on a white plastic tray (43 length $\times 43$ width $\times 12$ depth $\mathrm{cm})$ and covered with a cage constructed of wire and voile fabric $(62 \times 31 \times 31 \mathrm{~cm})$. In this assay, the transmission of the fungi I. fumosorosea ESALQ-1296 and $B$. bassiana ESALQ-PL63 from T. citricida cadavers and from $D$. citri cadavers to uninfected $D$. citri adults was examined using the same number of insects as the laboratory assays (1:20, 3:20, 5:20 and 10:20 sporulated:uninfected). The evaluations were performed on the 10th day by counting the number of dead insects to calculate the mortality of D. citri or $T$. citricida adults. Additionally, the number of infected and adhered insects on the plants was evaluated to estimate the potential of new cadavers for future transmission and dissemination in semi-field conditions. The experimental design was completely randomized with three replicates per treatment, and the experiment was repeated three times. In each experiment, a datalogger (IDEL Manaus HT-4000) was installed inside the cages to record the environmental conditions.

\section{Statistical analysis}

Negative binomial generalized linear models were fit to the data on the number of conidia per adult insect (sporulation) with a linear interaction predictor (fungal species $x$ insect species) because the data were overdispersed (Demétrio et al. 2014). When there was a significant difference between treatments, multiple comparisons were performed using the glht function of the multcomp package (Hothorn et al. 2008). The mortality rate and percentage of $D$. citri and $T$. citricida cadavers sporulated with the entomopathogenic fungi were evaluated in the transmission assays performed in the laboratory. In the semifield assays, the rate of mortality and number of cadavers adhered to the plant were evaluated. As these data consist of proportions and are overdispersed,

Table 1 Environmental conditions inside the cages used in the experiments examining the intraspecific (from $D$. citri to $D$.

transmission of entomopathogenic fungi under semi-field conditions in Piracicaba, São Paulo State, Brazil citri) and interspecific (from T. citricida to D. citri) horizontal

\begin{tabular}{llllll}
\hline Treatment & Experiments & $\begin{array}{l}\text { Date (month/ } \\
\text { day/year })\end{array}$ & $\begin{array}{l}\text { Mean temp. } \\
(\min -\max )\left({ }^{\circ} \mathrm{C}\right)^{\mathrm{a}}\end{array}$ & $\begin{array}{l}\text { Mean RH } \\
(\min -\max )(\%)^{\mathrm{b}}\end{array}$ \\
\hline From D. citri to D. citri & 1 & $03 / 15 / 2013$ & $25.1(15.4-43.5)$ & $74.7(34.7-96.8)$ & $\begin{array}{l}\text { Rainfall } \\
(\mathrm{mm})^{\mathrm{c}}\end{array}$ \\
& 2 & $03 / 27 / 2013$ & $23.4(17.0-39.0)$ & $81.6(40.9-96.7)$ & 129.5 \\
& 3 & $04 / 12 / 2013$ & $22.4(9.8-38.9)$ & $78.4(34.4-97.2)$ & 35.0 \\
From T. citricida to D. citri & 1 & $04 / 20 / 2013$ & $22.1(10.8-41.4)$ & $74.3(27.2-96.1)$ & 0 \\
& 2 & $05 / 03 / 2013$ & $19.9(4.7-41.1)$ & $74.3(25-96.4)$ & 0 \\
& 3 & $03 / 12 / 2014$ & $27.78(18.0-46.7)$ & $70.1(20.2-98.4)$ & 52.3 \\
\hline
\end{tabular}

\footnotetext{
a Temperature $\left({ }^{\circ} \mathrm{C}\right)$ mean (minimum and maximum)

${ }^{\mathrm{b}} \mathrm{RH}(\%)$ mean (minimum and maximum)

c Rainfall during the experimental period (ten days)
} 
quasi-binomial generalized linear models were fit with a logit link, first with different linear predictors per fungal species. Then, nested models with parallel linear predictors, coincident linear predictors and a null model were fit, and the significance of the effects was assessed using analysis of deviance tables. The coincident lines linear predictor was selected, which can be written as $\eta=\beta_{0}+\beta_{1} x$, where $\beta_{0}$ is the intercept, $\beta_{1}$ is the slope and $x$ is the number of sporulated cadavers. Goodness-of-fit was evaluated using half-normal plots with a simulated envelope (Demétrio et al. 2014). An analysis of deviance was performed to assess the significance of the interaction between the dates and treatments, and if the effect was non-significant $(P>0.05)$, the data from each date could be pooled in the same analysis. All analyses were carried out using the statistical software R ( R Development Core Team 2014).

\section{Results}

Sporulation of I. fumosorosea and B. bassiana on D. citri and T. citricida

The number of conidia produced by the fungi $I$. fumosorosea ESALQ-1296 and B. bassiana ESALQPL63 on the D. citri and T. citricida cadavers was evaluated to estimate the amount of inoculum with dispersion potential in the experimental units. The effect of the interaction between fungal species and pest species was significant $\left(\mathrm{F}_{1,12}=23.86\right.$, $P<0.001)$. The sporulation of $I$. fumosorosea was similar in adult $D$. citri and $T$. citricida. However, $B$. bassiana exhibited greater sporulation in adult $D$. citri than in adult $T$. citricida (Table 2).

Intraspecific horizontal transmission $(D$. citri $\rightarrow D$. citri) under laboratory conditions

The interaction between the dates and treatments was not significant $\left(\mathrm{F}_{14,48}=1.302, P=0.241\right)$, and the data from the three dates were therefore pooled in the analysis. There was no difference between the fungal species regarding mortality and sporulation (different vs. parallel linear predictors: $\mathrm{F}_{1,68}=0.044$, $P=0.834$; parallel vs. coincident linear predictors:
$\mathrm{F}_{1,69}=1.176, P=0.282$ for the mortality data; and different vs. parallel linear predictors: $\mathrm{F}_{1,68}=0.001$, $P=0.974$; parallel vs. coincident linear predictors: $\mathrm{F}_{1,69}=0.018, P=0.894$ for the sporulation data). Thus, the same regression curve was fit for B. bassiana ESALQ-PL63 and I. fumosorosea ESALQ-1296. Mortality and sporulation rates increased with the number of introduced cadavers, as indicated by the tests comparing the model with coincident linear predictors and the null model that was significant for both mortality $\left(\mathrm{F}_{1,70}=15.335, P<0.001\right)$ and sporulation $\left(\mathrm{F}_{1,70}=14.806, P<0.001\right)$ data. After the introduction of one to ten cadavers sporulated with $I$. fumosorosea and 20 uninfected adult $D$. citri, the mortality rate varied between 36.2 and $68.0 \%$ and sporulation between 34.3 and $67.4 \%$. However, when one or ten cadavers sporulating with B. bassiana were introduced, the mortality rate varied between 51.2 and $81.9 \%$ (Fig. 1a) and sporulation between 45.2 and $75.5 \%$ (Fig. 1b). The treatment in which no cadavers sporulating were introduced (control) exhibited a natural mortality rate of $12.0 \%$ (Fig. 1a), and these insects did not present fungal infections.

Interspecific horizontal transmission ( $T$.

citricida $\rightarrow$ D. citri) under laboratory conditions

The two fungal species caused similar mortality and sporulation (different vs. parallel linear predictors: $\mathrm{F}_{1,20}=0.360, P=0.555$; parallel vs. coincident linear predictors: $\mathrm{F}_{1,21}=1.258, P=0.4275$ for the mortality data; and different vs. parallel linear predictors: $\mathrm{F}_{1,20}=1.746, P=0.201$; parallel vs. coincident linear predictors: $\mathrm{F}_{1,21}=2.542, P=0.127$ for the sporulation data). Thus, the same regression curve was fit for B. bassiana and I. fumosorosea. The tests comparing the model with coincident linear predictors and the null model were significant for both mortality $\left(\mathrm{F}_{1,22}=19.793, \quad P<0.001\right) \quad$ and sporulation $\left(\mathrm{F}_{1,22}=4.542, P<0.046\right)$, indicating that mortality and sporulation rates increased with the number of sporulated cadavers (Fig. 2). The B. bassiana ESALQ-PL63 isolate caused 35.4 to $87.7 \%$ mortality at ratios of 1:20 to 10:20 (sporulated:uninfected), respectively. The mortality rates observed for $I$. fumosorosea ESALQ-1296 ranged from 41.7 to $80.4 \%$ at ratios of $1: 20$ to $10: 20$ (sporulated:uninfected), respectively (Fig. 2a). The percentage of dead 
Table 2 Number of conidia produced by Isaria fumosorosea ESALQ-1296 and Beauveria bassiana ESALQ-PL63 in sporulating cadavers of Diaphorina citri and Toxoptera citricida

\begin{tabular}{llc}
\hline Fungal Species & \multicolumn{2}{l}{ Means of Conidia number $\left(\times 10^{6}\right)$ per cadaver $\pm \mathrm{SE}^{\mathrm{a}}$} \\
\cline { 2 - 3 } & Diaphorina citri & Toxoptera citricida \\
\hline Beauveria bassiana ESALQ-PL63 & $4.14 \pm 0.44 \mathrm{aA}$ & $1.06 \pm 0.03 \mathrm{bB}$ \\
Isaria fumosorosea ESALQ-1296 & $3.02 \pm 0.22 \mathrm{aA}$ & $3.29 \pm 0.30 \mathrm{aA}$
\end{tabular}

${ }^{a}$ Lower-case letters represent differences within a column (fungi), and upper-case letters represent differences within rows (insect) by multiple comparisons test $(P<0.05)$

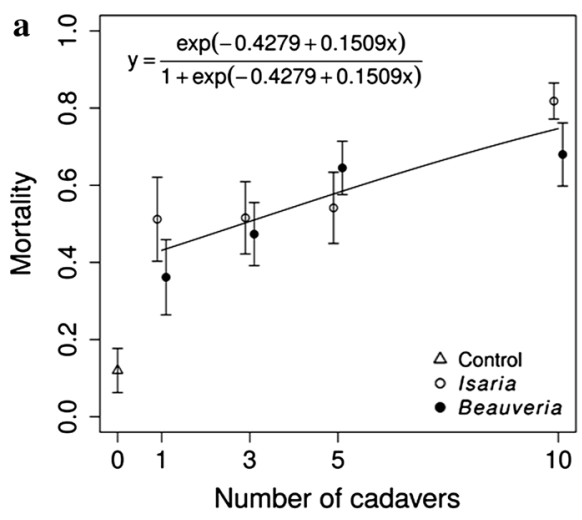

Fig. 1 Model fit for mortality (a) and sporulation (b) of adult Diaphorina citri after ten days of the introduction of different numbers of Diaphorina citri cadavers with conidia of Isaria fumosorosea and Beauveria bassiana at temperature of

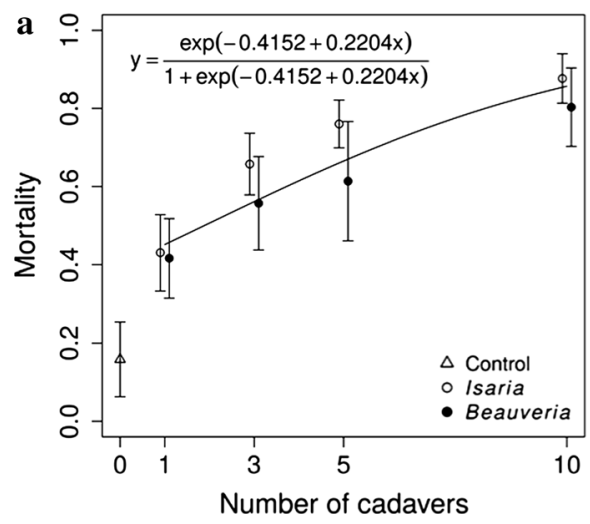

Fig. 2 Model fit for mortality (a) and sporulation (b) of adult Diaphorina citri after ten days of the introduction of different numbers of Toxoptera citricida cadavers with conidia of Isaria fumosorosea and Beauveria bassiana at temperature of

insects with I. fumosorosea and B. bassiana spores ranged from 38.3 to $77.0 \%$ and 14.5 to $65.3 \%$, respectively (Fig. 2b). The treatment in which no

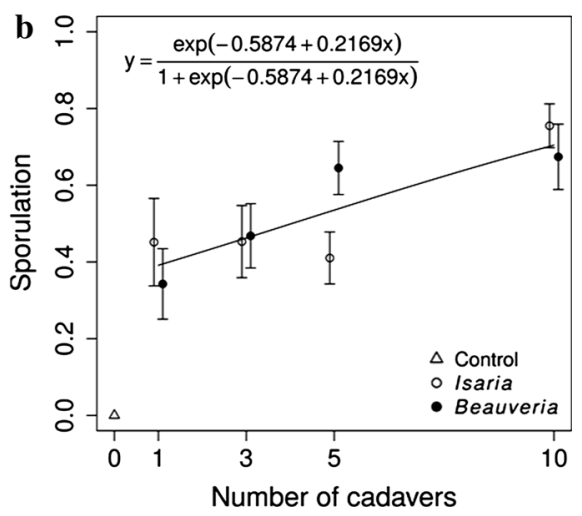

$25 \pm 2{ }^{\circ} \mathrm{C}, 80 \pm 10 \% \mathrm{RH}$ and $12 \mathrm{~h}$ photophase. The same regression curve was fitted for both fungal species. Plotted values represent means while bars represent SE

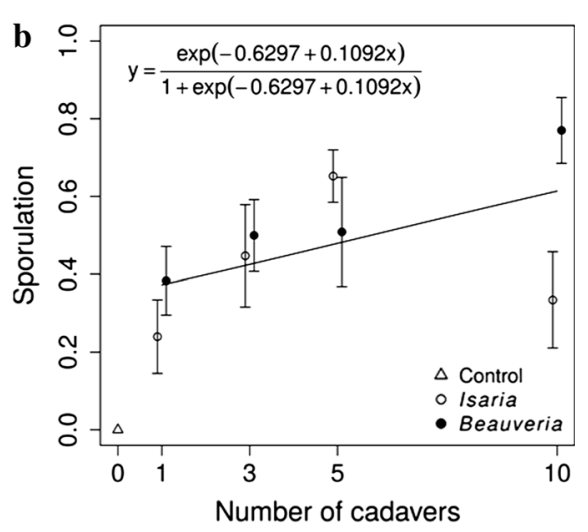

$25 \pm 2{ }^{\circ} \mathrm{C}, 80 \pm 10 \% \mathrm{RH}$ and $12 \mathrm{~h}$ photophase. The same regression curve was fitted for both fungal species. Plotted values represent means while bars represent $\mathrm{SE}$

sporulated cadavers were introduced (control) exhibited a natural mortality rate of $15.8 \%$ (Fig. 2a), and these insects did not present fungal infections. 
Intraspecific horizontal transmission

(D. citri $\rightarrow$ D. citri) under semi-field conditions

The analysis of deviance demonstrated no significant interaction between the assays and treatments $\left(\mathrm{F}_{14,48}=1.37, P=0.21\right)$, and the assays showed the same trend, so only the last one was presented. Similar to the laboratory experiment, no differences were observed in horizontal transmission between the fungal species. Thus, the same regression curve was fit for both B. bassiana ESALQ-PL63 and I. fumosorosea ESALQ-1296 (different vs. parallel linear predictors: $\mathrm{F}_{1,20}=0.086, P=0.773$; parallel vs. coincident linear predictors: $\mathrm{F}_{1,21}=1.005, P=0.328$ ). However, the test between the model with coincident linear predictors and the null model was non-significant $\left(\mathrm{F}_{1,22}=4.317, P=0.051\right)$, so the mortality rate was not influenced by the number of cadavers under semifield conditions. The mortality rates ranged from 26.7 to $58.3 \%$ for B. bassiana and 16.7 to $56.7 \%$ for $I$. fumosorosea (Fig. 3). Although greater variance in the mortality rates within and between replicates was observed, an increase in mortality related to increases in the number of cadavers was observed, which was similar to the results of the experiments conducted under laboratory conditions. After ten days, relatively low percentages of infected $D$. citri adults remained adhered and sporulated on the plants, and the number of adults did not vary significantly according to the number of sporulated cadavers released. The

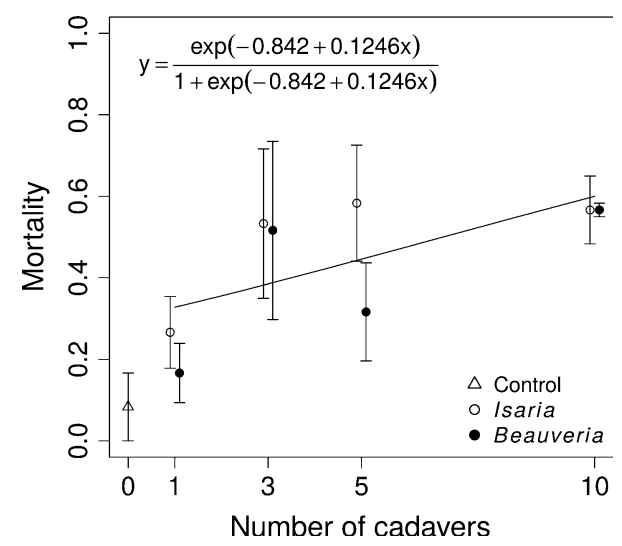

Fig. 3 Model fit for mortality of adult Diaphorina citri after ten days of the introduction of different numbers of $D$. citri cadavers with conidia of Isaria fumosorosea and Beauveria bassiana in semi-field conditions. The same regression curve was fitted for both fungal species. Plotted values represent means while bars represent SE percentage of dead insects and insects adhered to the plants did not vary significantly as the number of sporulated cadavers released increased $\left(\mathrm{F}_{7,16}=1.69\right.$, $P=0.18$ ). Only $1.7,3.3,8.3$ and $20.0 \%$ of the dead insects remained adhered to the plant when the fungus B. bassiana was used at ratios of 1:20, 3:20, 5:20 and 10:20 (sporulated:uninfected), respectively. However, 5.0, 11.7, 11.7 and $18.3 \%$ of the dead insects remained adhered to the plant when the fungus $I$. fumosorosea was used at ratios of 1:20, 3:20, 5:20 and 10:20 (sporulated:uninfected), respectively. The environmental conditions were characterized by large temperature $\left(9.8-39{ }^{\circ} \mathrm{C}\right)$, $\mathrm{RH} \quad(34.4-97.2 \%)$ and rainfall ranges $(15.5-129.5 \mathrm{~mm})$ during the experimental period (Table 1).

Interspecific horizontal transmission

(T. citricida $\rightarrow D$. citri) under semi-field conditions

The analysis of deviance showed no significant interaction between the assays and treatments $\left(\mathrm{F}_{7,32}=1.25, P=0.31\right)$, and the assays showed the same trend, so only the last one was presented. The introduction of $T$. citricida cadavers sporulated with $I$. fumosorosea ESALQ-1296 and B. bassiana ESALQPL63 resulted in mortality rates of $D$. citri that ranged from 31.7 to $53.3 \%$ and 15.0 to $38.3 \%$, respectively (Fig. 4). No differences in horizontal transmission were observed between the fungal species. Thus, the same regression curve was fitted for both $B$. bassiana and I. fumosorosea (different vs. parallel linear predictors: $\mathrm{F}_{1,20}=0.113, P=0.741$; parallel vs. coincident linear predictors: $\mathrm{F}_{1,21}=0.654$, $P=0.428$ ). Mortality rates were not influenced by the number of cadavers under semi-field conditions, as indicated by the non-significant tests comparing the model with coincident linear predictors and the null model $\left(\mathrm{F}_{1,22}=0.286, P=0.599\right)$. Although considerable mortality levels caused by the transmission of the entomopathogenic fungi were observed, no significant differences were observed between the treatments. In this experiment, less than $5.0 \%$ of the dead adult $D$. citri were observed adhering to the plants. The environmental conditions were characterized by wide ranges of temperature $\left(4.7-46.7{ }^{\circ} \mathrm{C}\right)$, $\mathrm{RH}$ (20.2-98.4\%) and rainfall $(0-52.3 \mathrm{~mm})$ during the experimental period (Table 1). 


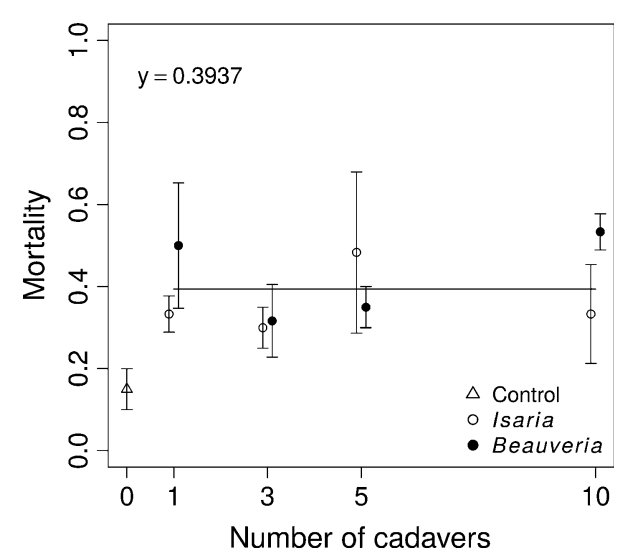

Fig. 4 Model fit for mortality of adult Diaphorina citri after ten days of the introduction of different numbers of Toxoptera citricida cadavers with conidia of Isaria fumosorosea and Beauveria bassiana in semi-field conditions. The same regression curve was fitted for both fungal species. All other parameters but the intercept were not significant (test for different linear predictors vs. null model: $F_{3,20}=0.35$, $P=0.79$ ). Plotted values represent means while bars represent SE

\section{Discussion}

The two fungal isolates used in the current study, $I$. fumosorosea ESALQ-1296 and B. bassiana ESALQPL63, were selected based on high mortality (62.8 and $59.7 \%$, respectively) and sporulation (41.1 and 37.9.3\%, respectively) in adult $D$. citri ten days after treatment with a suspension of $5 \times 10^{6}$ conidia $\mathrm{ml}^{-1}$ (unpublished data). Additionally, it was demonstrated that I. fumosorosea ESALQ-1296 caused higher mortality $(65.4 \%)$ and sporulation $(64.2 \%)$ than $B$. bassiana ESALQ-PL63 (mortality of $42.7 \%$ and sporulation of $26 \%$ ) in $T$. citricida adults ten days after treatment with a suspension of $5 \times 10^{6}$ conidia $\mathrm{ml}^{-1}$ (unpublished data). Therefore, biological control of citrus pests can be enhanced by transmission and dissemination of B. bassiana and I. fumosorosea between different insect species that share the same habitat, such as D. citri and T. citricida.

The sporulation of entomopathogenic fungi on a host is an important characteristic because conidia serve as a source of pathogen inocula for horizontal transmission, ecosystem dissemination and infection cycle development (Hesketh et al. 2010). The number of conidia produced by I. fumosorosea ESALQ-1296 was similar to the number produced by B. bassiana ESALQ-PL63 in D. citri cadavers. However, sporulation in T. citricida cadavers was three times higher for the ESALQ-1296 isolate compared with the ESALQ-PL63 isolate. The production of conidia in cadavers is known to vary according to the fungal species, host species, insect size and developmental stage (Sosa-Gómez and Alves 2000; Steinkraus 2006).

The results of the present study demonstrated that considerable horizontal transmission of the fungi $I$. fumosorosea ESALQ-1296 and B. bassiana ESALQPL63 occurs between D. citri individuals (intraspecific). The horizontal transmission potential of both entomopathogenic fungi between $D$. citri individuals was similar, which may be associated with the similar average production of conidia in the cadavers quantified in the study described herein. The increase in the mortality of adult $D$. citri was correlated with the increase in the inoculum source (number of sporulated insects per plant), which may have resulted in greater acquisition and dissemination of the conidia at the site. Using a different method from that used in the present study, Moran et al. (2011) demonstrated the transmission rates of $I$. fumosorosea blastopores impregnated on yellow card between infected and uninfected $D$. citri (1:1.5 treated:healthy ratio) were approximately $25 \%$ after three week, which were lower than rates obtained in the present study when using ten $D$. citri cadavers and 20 healthy adults (1:2 ratio). The horizontal transmission of $B$. bassiana has been shown to be affected by the amount of conidia, density of cadavers, host development stage and the environmental conditions in other agricultural pests (Long et al. 2000).

The present study demonstrated and quantified the potential for interspecific horizontal transmission of the entomopathogenic fungi $B$. bassiana ESALQ-PL63 and I. fumosorosea ESALQ-1296 between T. citricida cadavers and healthy adult $D$. citri. Although the sporulation of I. fumosorosea on T. citricida cadavers was greater than that of the B. bassiana isolate, the interspecific horizontal transmission observed under laboratory conditions was similar to the intraspecific transmission of both entomopathogenic fungi. This may be associated with factors such as fungal virulence and dissemination potential or host susceptibility.

HLB disease has increased significantly in citrus orchards in recent years. The acceptable level of the HLB insect vector, D. citri, is extremely low (near zero). Therefore, insecticides are usually used to control this vector, which has resulted in increased 
production costs (FNP 2013). In Brazil, many farmers have ceased control of the vector in older groves, organic groves, and residential groves. The population levels of the aphid T. citricida, a vector of CTV, are usually higher than those of $D$. citri because of the use of rootstock resistant to CTV as well as varieties preimmunized with mild strains of CTV (Meissner Filho et al. 2002). Both insects prefer leaves and green shoot branches (Gravena 2005), and the efficiency of D. citri and $T$. citricida control by the entomopathogenic fungi I. fumosorosea and B. bassiana in citrus groves may therefore be improved due to both intra- and interspecific horizontal transmission.

Horizontal transmission under semi-field conditions resulted in lower mortality rates of adult $D$. citri compared with the laboratory assays, which may have been caused by the larger size of the experimental units used in the field and environmental conditions and the associated greater temperatures, humidity range, wind and rainfall. Baverstock et al. (2010) indicated that a positive relationship occurs between insect movement and horizontal transmission of entomopathogenic fungi. Therefore, the smaller size of the containers used in the laboratory assays could have increased the direct contact between the insects and cadavers with conidia. The density of individuals may have influenced the transmission and dissemination of conidia. Although wind is an important factor in conidial dissemination, it may have facilitated the dissemination of conidia out of the cages. Despite the occurrence of high rainfall after the release of cadavers into the experimental units, which may have removed the cadavers from the leaves, considerable levels of mortality caused by the fungi were still observed under semi-field conditions.

Diaphorina citri nymphs as well as T. citricida wingless adults and nymphs are gregarious (Tsai and Liu 2000; Toledo et al. 2006), and this behavior may favor the transfer of conidia between individuals and increase the efficiency of entomopathogenic fungi in controlling D. citri in citrus orchards. The level of horizontal transmission of the entomopathogenic fungi I. fumosorosea and B. bassiana observed in the present study under laboratory and semi-field conditions depended on the level of sporulation and host density in the field. Sporulation on cadavers is associated with periods of high RH, which occur mostly from November to March in São Paulo, Brazil (Italo Delalibera Junior unpublished data). If other citrus pest species are affected by the same entomopathogenic fungi and their cadavers exhibit sporulation in the field, the control of such pests could be improved. In abandoned and residential areas, D. citri and $T$. citricida densities are high, and after spray application of I. fumosorosea and B. bassiana, these insects could exhibit sporulation and horizontal transmission, which might increase D. citri control in citrus groves. Farmers who carry out intensive management of D. citri in Brazil are controlling the pest even in neighboring areas where $D$. citri control has been abandoned, to prevent migration into their groves. We anticipate greater adoption of biological control in these less intensively managed areas, where the host populations are usually greater, which may improve the efficacy of fungal applications for controlling $D$. citri populations in the field. Other factors, such as removal of cadavers by ants, may decrease transmission in the field (Nielsen et al. 2010). In the semi-field experiments, we observed that a low percentage of the dead adult $D$. citri were adhered to the plants, and ants of the genera Dorymyrmex and Brachymyrmex were observed removing dead insects. For these reasons, long-term field studies are needed to confirm the results obtained here under laboratory and semi-field conditions.

Acknowledgments The authors would like to thank the Foundation of Citrus Growers of São Paulo State (Fundação dos Citricultores do Estado de São Paulo-FUNDECITRUS) and São Paulo State Research Foundation (Fundação de Amparo à Pesquisa do Estado São Paulo-FAPESP-IMBICONT Project number 2011/51556-3) for the financial support. The first author has a master's scholarship provided by the Coordination for the Improvement of Higher Education Personnel (Coordenação de Aperfeiçoamento de Pessoal de Nível Superior-CAPES).

\section{References}

Alves SB (1998) Controle Microbiano de Insetos, 2nd edn. FEALQ, Piracicaba

Avery PB, Hunter WB, Hall DG, Jackson MA, Powell CA, Rogers ME (2009) Diaphorina citri (Hemiptera: Psyllidae) infection and dissemination of the entomopathogenic fungus Isaria fumosorosea (Hypocreales: Cordycipitaceae) under laboratory conditions. Fla Entomol 92:608-618

Avery PB, Queeley GL, Faull J, Simmonds MSJ (2010) Effect of photoperiod and host distribution on the horizontal transmission of Isaria fumosorosea (Hypocreales: Cordycipitaceae) in greenhouse whitefly assessed using a novel model bioassay. Biocontrol Sci Technol 20(10):1097-1111 
Balfour A, Khan A (2012) Effects of Verticillium lecanii (Zimm.) Viegas on Toxoptera citricida Kirkaldy (Homoptera: Aphididae) and its parasitoid Lysiphlebus testaceipes Cresson (Hymenoptera: Braconidae). Plant Prot Sci 48(3): 123-130

Baverstock J, Roy HE, Pell JK (2010) Entomopathogenic fungi and insect behavior: from unsuspecting hosts to targeted vectors. BioControl 55:89-102

Bové JM (2006) Huanglongbing: a destructive, newly-emerging, century-old disease of citrus. J Plant Pathol 88:7-37

Casique-Valdes R, Reyes-Martinez Y, Sanchez-Peña SR, Bidochka MJ, Lopez-Arroyo JI (2011) Pathogenicity of Hirsutella citriformis (Ascomycota: Cordicipitaceae) to Diaphorina citri (Hemiptera: Psyllidae) and Bactericera cockerelli (Hemiptera: Triozidae). Fla Entomol 94(3): 703-705

FNP Consultoria \& Comércio (2013) Tomada de decisão em laranjais pede cautela. In: AGRIANUAL 2013: Anuário da Agricultura Brasileira. São Paulo, pp 249-250

Demétrio CGB, Hinde J, Moral RA (2014) Models for overdispersed data in entomology. In: Godoy WAC, Ferreira CP (eds) Ecological modelling applied to entomology. Springer, Switzerland, pp 219-259

Gandarilla-Pacheco FL, Gálan-Wong LJ, Arroyo JI, RodríguezGuerra R, Quintero-Zapata I (2013) Optimization of pathogenicity tests for selection of native isolates of entomopathogenic fungi isolated from citrus growing areas of México on adults of Diaphorina citri Kuwayama (Hemiptera: Liviidae). Fla Entomol 96(1):187-195

García-Munguía AM, Garza-Hernández JA, Rebollar-Tellez EA, Rodríguez-Pérez MA, Reyes-Villanueva F (2011) Transmission of Beauveria bassiana from male to female Aedes aegypti mosquitoes. Parasit Vectors 4:24-29

Gravena S (2005) Manual prático de manejo ecológico de pragas dos citros. In: Gravena S (ed) As pragas. Jaboticabal, São Paulo, pp 69-220

Hajek AE, St. Leger RJ (1994) Interactions between fungal pathogens and insects hosts. Annu Rev Entomol 39:293-322

Hall DG, Hentz MG, Meyer JM, Kriss AB, Gottwald TR, Boucias DG (2012) Observations on the entomopathogenic fungus Hirsutella citriformis attacking adult Diaphorina citri (Hemiptera: Psyllidae) in a managed citrus grove. BioControl 57:663-675

Harper JD (1987) Applied epizootiology: microbial control of insects. In: Fuxa JR, Tanada Y (eds) Epizootiology of insect diseases. Wiley, New York, pp 473-496

Hernández-Torres I, López-Arroyo JI, Berlanga-Padilla A, Loera-Gallardo J, Acosta-Díaz E (2006) Efectividad de hongos entomopatógenos y vehículos de aplicación para el control del pulgón café de los cítricos Toxoptera citricida Kirkaldy (Homoptera: Aphididae). Vedalia 13(1):17-26

Hesketh H, Roy HE, Eilenberg J, Pell JK, Hails RS (2010) Challenges in modelling complexity of fungal entomopathogens in semi-natural populations of insects. BioControl 55:55-73

Hothorn T, Bretz F, Westfall P (2008) Simultaneous inference in general parametric models. Biom J 50:346-363

Hoy MJ, Singh R, Rogers ME (2010) Evaluations of a novel isolate of Isaria fumosorosea for control of the Asian citrus psyllid, Diaphorina citri (Hemiptera: Psyllidae). Fla Entomol 93:24-32

Hunter WB, Avery PB, Pick D, Powell CA (2011) Broad spectrum potential of Isaria fumosorosea against insect pests of citrus. Fla Entomol 94(4):1051-1054

Kuchment A (2013) The end of orange juice. Sci Am 308:52-59

Lezama-Gutiérrez R, Molina-Ochoa J, Chávez-Flores O, ÁngelSahagún CA, Skoda SR, Reyes-Martínez G, Barba-Reynoso M, Rebolledo-Domínguez O, Ruíz-Aguilar GML, Foster JE (2012) Use of the entomopathogenic fungi $M e$ tarhizium anisopliae, Cordyceps bassiana and Isaria fumosorosea to control Diaphorina citri (Hemiptera: Psyllidae) in Persian lime under field conditions. Int J Trop Insect Sci 32(1):39-44

Long DW, Groden E, Drummond FA (2000) Horizontal transmission of Beauveria bassiana (Bals.) Vuill. Agric For Entomol 2:19-32

Lopes RB, Micherreff-Filho M, Tigano MS, Neves PMOJ, López EL, Fancelli M, Silva JP (2011) Virulence and horizontal transmission of selected Brazilian strains of Beauveria bassiana against Cosmopolites sordidus under laboratory conditions. Bull Insectol 64(2):201-208

Meissner Filho JO, Soares Filho WS, Velame KVC, Diamantino EP, Diamantino MSAS (2002) Reação de Porta enxerto híbridos ao Citrus Tristeza Virus. Fitopatol Bras 27:312-315

Meyer JM, Hoy MA, Boucias DG (2007) Morphological and molecular characterization of a Hirsutella species infecting the Asian citrus psyllid, Diaphorina citri Kuwayama (Hemiptera: Psyllidae) in Florida. J Invert Pathol 95:101-109

Meyer JM, Hoy MA, Boucias DG (2008) Isolation and characterization of an Isaria fumosorosea isolate infecting the Asian citrus psyllid in Florida. J Invert Pathol 99:96-102

Michaud JP (1998) A Review of the literature on Toxoptera citricida (Kirkaldy) (Homoptera: Aphididae). Fla Entomol 81(1):37-61

Moran PJ, Patt JM, Cabanillas HE, Adamczyk JL, Jackson MA, Dunlap CA, Hunter WB, Avery PB (2011) Localized autoinoculation and dissemination of Isaria fumosorosea for control of the Asian citrus psyllid in south Texas. Sub Plant Sci 63:23-35

Nielsen C, Agrawal AA, Hajek AE (2010) Ants defend aphids against lethal disease. Biol Lett 6:205-208

Padulla LFL, Alves SB (2009) Suscetibilidade de ninfas de Diaphorina citri a fungos entomopatogênicos. Arq Inst Biol 76:297-302

Pick DA, Avery PB, Hunter WB, Powell CA, Arthurs S (2012) Effect of Isaria fumosorosea (Hypocreales: Cordycipitaceae) and Lysiphlebus testaceipes, (Hymenoptera: Braconidae) on the brown citrus aphid: preliminary assessment of a compatibility study. Fla Entomol 95(3):764-766

Pinto APF, Batista Filho A, Almeida JEM, Wenzel IM (2012) Patogenicidade de Beauveria bassiana ao psilídeo Diaphorina citri e compatibilidade do fungo com produtos fitossanitários. Pesqui Agropecu Bras 47(12):1673-1680

Poprawski TJ, Parker PE, Tsai JH (1999) Laboratory and field evaluation of hyphomycete insect pathogenic fungi for control of brow citrus aphid (Homoptera: Aphididae). Environ Entomol 28:315-321 
Quesada-Moraga E, Martin-Carballo I, Garrido-Jurado I, Santiago-Álvarez C (2008) Horizontal transmission of $\mathrm{Me}$ tarhizium anisopliae among laboratory populations of Ceratitis capitata (Wiedemann) (Diptera: Tephritidae). Biol Control 47:115-124

R Development Core Team (2014) R: A language and environment for statistical computing. R Foundation for Statistical Computing, Vienna, Austria. ISBN 3-900051-07-0. http://www.R-project.org/

Sanjaya Y, Ocampo VR, Caoili BL (2013) Transmission effect of entomopathogenic fungi on population of Tetanychus kanzawai (Kishida) (Tetranychidae: Acarina). Arthropods 2(1):36-41

Sosa-Gómez DR, Alves SB (2000) Temperature and relative humidity requirements for conidiogenesis of Beauveria bassiana (Deuteromycetes: Moniliaceae). An Soc Entomol Bras 29(3):515-521

Stauderman K, Avery P, Aristizábal L, Arthurs S (2012) Evaluation of Isaria fumosorosea (Hypocreales: Cordycipitaceae) for control of the Asian citrus psyllid, Diaphorina citri (Hemiptera: Psyllidae). Biocontrol Sci Technol 22(7):747-761

Steinkraus DC (2006) Factors affecting transmission of fungal pathogens of aphids. J Invert Pathol 92:125-131

Subandiyah S, Nikoh N, Sato H, Wagiman F, Tsuyumu S, Fukatsu T (2000) Isolation and characterization of two entomopathogenic fungi attacking Diaphorina citri (Homoptera, Psylloidea) in Indonésia. Mycoscience 41:509-513

Svedese VM, Lima EALA, Figueiredo AL (2013) Horizontal transmission and effect of the temperature in pathogenicity of Beauveria bassiana against Diatraea saccharalis (Lepidoptera: Crambidae). Braz Arch Biol Technol 56(3):413-419

Toledo FR, Barbosa JC, Yamamoto PT (2006) Distribuição espacial de Toxoptera citricida Kirkaldy (Hemiptera: Aphididae) na cultura de citros. Rev Bras Frutic 28(2):194-198

Toledo J, Campos SE, Flores S, Liedo P, Barrera JF, Villaseñor A, Montoya P (2007) Horizontal transmission of Beauveria bassiana in Anastrepha ludens (Diptera: Tephritidae) under laboratory and field cage conditions. J Econ Entomol 100(2):291-297
Tsai JH, Liu YH (2000) Biology of Diaphorina citri (Homoptera: Psyllidae) on four host plants. J Econ Entomol 93(6):1721-1725

Yang Y, Huang M, Andrew G, Beattie C, Xia Y, Ouyang G, Xiong J (2006) Distribution, biology, ecology and control of the psyllid Diaphorina citri Kuwayama, a major pest of citrus: a status report for China. Int J Pest Manag 52(4):343-352

Marcos Roberto Conceschi is currently a $\mathrm{PhD}$ student at the Department of Entomology and Acarology of the "Luiz de Queiroz" College of Agriculture (ESALQ), University of São Paulo (USP, Brazil) and he is interested on citrus pest and biological control.

Celeste Paola D'Alessandro is a post-doctoral research associate at Department of Entomology and Acarology, ESALQ-USP, Brazil, and her research experience is on insect pathology and biological control with emphasis on entomopathogenic fungi.

Rafael de Andrade Moral is a PhD student at Department of Exact Sciences, ESALQ-USP, Brazil, and is involved in developing statistical models using ecological and entomological data with emphasis on biological control.

Clarice Garcia Borges Demétrio is a professor at the Department of Exact Sciences, ESALQ-USP, Brazil, and is a specialist in generalized linear models and extensions, with emphasis on mixed models and models for zero-inflated and overdispersed data. She is past president of the International Biometric Society (2012-2013).

Italo Delalibera Júnior is a professor at Department of Entomology and Acarology, ESALQ-USP, Brazil, and is a specialist in microbe-arthropod interactions, with emphasis on microbial control of agricultural pests with several microbial entomopathogens and professor of undergraduate courses in zoology and graduate courses in arthropod pathology and microbial control of pests. 